\title{
The Canadian Journal of Psychiatry
}

Volume 59, Number 12

December 2014

\section{For How Long Should We Use Symptomatic Therapies to Treat People With Alzheimer Disease?}

\author{
Kenneth Rockwood, MD, FRCPC, FRCP1 \\ ${ }^{1}$ Professor of Medicine, Divisions of Geriatric Medicine and Neurology, Department of Medicine, Dalhousie University, Nova Scotia; Kathryn Allen Weldon \\ Professor of Alzheimer Research, Staff Physician, Centre for Health Care of the Elderly and Department of Medicine, Queen Elizabeth II Health Science \\ Centre, Capital District Health Authority, Halifax, Nova Scotia. \\ Correspondence: Centre for Health Care of the Elderly, Room 1421, 1st Floor, CHVMB, 5955 Veterans' Memorial Lane, Halifax, NS B3H 2E1; \\ kenneth.rockwood@dal.ca.
}

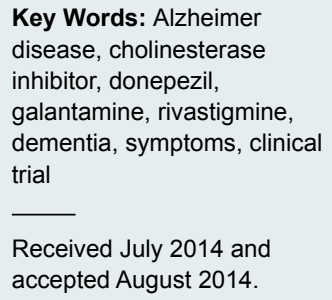

Received July 2014 and accepted August 2014.

$\mathrm{P}$ hysicians who treat people with Alzheimer disease face the common challenge of how to extrapolate from the evidence base to the individual patient who comes to them for help. In dementia care, this can be a fractious undertaking. Sometimes the evidence is read to support starting treatment, ${ }^{1,2}$ and sometimes the same evidence is read as largely against using cholinesterase inhibitors (ChEIs) to treat people with dementia. ${ }^{3}$ The 2 In Review papers in this issue ${ }^{4,5}$ offer some guidance on a related question, for which the evidence also is only a rough guide. Dr David B Hogan, ${ }^{4}$ having evaluated the literature on whether treatment has long-term efficacy, concludes that there is evidence to suggest that it may, but that treatment effects do not last for most people. Sensibly, he suggests judicious individualization, taking into account the patient's state, and whether, on treatment, their condition seems to have benefited, recognizing that benefit may manifest only in a sense of slowed progression. He acknowledges that this is an imperfect guide, but given that we will not have treatment trials that last for many years, it is with what we must work. Dr Colleen J Maxwell and colleagues ${ }^{5}$ have reviewed the data on persistence and adherence. Their analyses are complementary in suggesting the importance of prescriber-patient communication in adherence. Even so, they note evidence that suggests that there are not only patient and drug characteristics but also system and prescriber ones that influence who stays on treatment and who does not. The latter also likely reflects, at least in part, variability in interpretation of the evidence.

Thus if treatment does not work for everyone, what is a physician to do? What guides individualization? This physician grew up in the shadow of the steeple, in an era of hope in ecumenical bible study. The experience left me unpersuaded by the idea that intelligent people of good will can all just calmly look at the evidence and come to a shared conclusion about what it says. (However, I do remain persuaded that intelligent people of good will should get along with each other, for which mutual respect offers a firm start.) Instead, as Dr Maxwell and colleagues ${ }^{5}$ show us, context matters, as does the outlook of the observer.

The first question is whether to start treatment at all. For me, the clinical trials' data show that, compared with placebo, more people benefit in a statistically significant, doseresponsive manner. ${ }^{6}$ These results, in which the evidence converges within trials and is replicable across trials, are for me persuasive, ${ }^{6}$ and meet a priori criteria for clinical meaningfulness. ${ }^{7}$ Further, I believe that, with the possible exception of the stage of the 
dementia, the data offer little guidance in knowing which patients will benefit, and even less on how they will benefit. In consequence, my practice is to offer a treatment trial with a ChEI to all patients, except those (in my experience very few) who suggest otherwise at the outset.

Conversely, I know colleagues who view the matter differently, who are scrupulous in checking for contraindications and somewhat less than fully persuasive with patients on the merit of a treatment trial. Such experience leads me to believe that, even at the level of a specialist referral, whether patients get started on treatment depends on who they see, even though each can point to guidelines in support of the position that they hold. ${ }^{1-3}$

Once treatment has been started, the next question is to know whether to keep going. I track benefit by seeing whether treatment meets goals based on the symptoms that they and their families define as being most salient. My practice is to aim at targets based on symptoms that are important to patients - verbal repetition being one example. ${ }^{8}$ Even so, as argued elsewhere, the most salient target symptoms have to do with executive function, which largely went unmeasured in the pivotal trials of ChEIs. ${ }^{9}$

If whether to start treatment (for which there are controlled trials) is contentious, then whether to continue might be expected to be even more so, as the data are less clear. Nevertheless, as Dr Hogan notes, ${ }^{4}$ a survey of Canadian specialists shows essentially no support for routinely stopping treatment based solely on how long a patient has been taking a ChEI. ${ }^{10}$ Similarly, once treatment has been started, one suspects that there would be little professional support for a physician who appeared to be indifferent to reports that patients had gotten worse after treatment had stopped. Again, as Dr Hogan has pointed out, there is some evidence that deterioration after stopping is real, can occur later in the disease course, and is sometimes the clearest way to make the benefits of treatment evident.

However, we would miss out were we to read these reviews as simply supporting current practice. First, not all patients with dementia are diagnosed, and of those who are, not all are treated. The 2 points are not unrelated. The legacy of therapeutic nihilism in dementia includes what amounts to a de facto endorsement of the many physicians who opt out of dementia care. These physicians typically argue that, because the drugs do not work, there really is nothing to be done, and therefore little point in screening for dementia or even in knowing much about it.

If this not-uncommon nihilism is the price of the autonomy needed for professionalism, then it is a steep one. Conversely, more pragmatic data to guide care may help to counter nihilism. As the reviews $s^{4,5}$ have pointed out, it is not as if a physician would be expected to stop prescribing at 6 or even 12 months. Studies with blinded withdrawal in the face of uncertain benefit were done, but not required. Little guidance was offered about how to track treatment in usual care. The Alzheimer Disease Assessment scale - cognitive subsection (or ADAS-Cog), ${ }^{11}$ an instrument almost entirely restricted to research studies, still dominates in trials, and most instruments competing for hegemony show little evidence of being any more user friendly.

Biomarkers have been the focus of heavy investment. Had they proven to be responsive surrogates for clinically important change, the expectation appears to have been that they would have greatly simplified the assay of effectiveness - as I heard one pharma scientist comment, without irony, at an industry-regulatory roundtable, "We need our own cholesterol!" Given how events have unfolded, including a 2013 FDA Guidance that noted that "no reliable evidence exists at the present time that any observed treatment effect on such a measure (biomarker) is reasonably likely to predict ultimate clinical benefit," $12, \mathrm{p} 5$ how realistic this expectation was is unclear.

In recognition of how serious the challenge of dementia is to aging societies, the Group of Eight (as it was then) in December 2013 had a rare disease summit on dementia. Accompanying the declining hope of disease modification anytime soon, the last few years have also seen the return to studies of symptomatic drug treatment. Given that we now have a standard of care, and therefore no threat of extended purely placebo treatment, there may be room for longer studies of these agents. Likewise, adaptive designs may lessen the cost of longer trials if no benefit emerges. ${ }^{13}$ Better licensing may require some trade-off between a more rapid approval, or conditional approval, with longer and withdrawal studies to follow. Such methodological and regulatory reforms were among the many discussed at the follow-up Group of Seven Global Action Against Dementia meeting that took place in London on July 19, 2014. Those discussions also included how to accelerate drug development by mitigating risk to industry. The description of how risk to industry may be mitigated included pointed comments about how better data sharing may mean pharma less often playing magnet ball (that is, all running after the same target). Even so, most of the reforms, including social investment and various public and (or) private philanthropic schemes were strongly market-driven. (The market counter to that last assertion is that any company going after massive reward would better structure its internal incentives so as to induce risk taking at the clinical trial level.)

As the reviews by $\mathrm{Dr} \operatorname{Hogan}^{4}$ and $\operatorname{Dr}$ Maxwell and colleagues $^{5}$ make clear, the evidence now suggests a considerable degree of interpretation remains in the data we possess. An important lesson is that we need to aim higher in clinical trial programs. Against an exclusive reliance on industry, some thought should be given to ensuring affordable dementia treatments. Either way, we will need an evidence base that is informative enough that we can be clear about what to do for the individual patients in front of us.

\section{Acknowledgements}

Dr Rockwood is founder, President, and holds shares in DGI Clinical, a spin-off company that promotes 
individualized outcomes measurement and has contracts with pharma. He also participated in an advisory board meeting for Roche in 2014 and for Merck in 2012, and gave a talk at the International Conference on Alzheimer Disease in Honolulu in 2010 that was sponsored by Bristol-Myers Squibb. In 2010, he testified on behalf of Eisai Japan in a patent dispute in Canada.

Dr Rockwood receives career support from the Dalhousie Medical Research Foundation as the Kathryn Allen Weldon Professor of Alzheimer Research.

The Canadian Psychiatric Association proudly supports the In Review series by providing an honorarium to the authors.

\section{References}

1. Birks J. Cholinesterase inhibitors for Alzheimer's disease. Cochrane Database Syst Rev. 2006;(1):CD005593.

2. Gauthier S, Patterson C, Chertkow H, et al. Recommendations of the 4th Canadian Consensus Conference on the Diagnosis and Treatment of Dementia (CCCDTD4). Can Geriatr J. 2012;15(4):120-126; and simultaneously in Can J Neurol Sci. 2012;39(6 Suppl 5):S1-S8.

3. Raina P, Santaguida P, Ismaila A, et al. Effectiveness of cholinesterase inhibitors and memantine for treating dementia: evidence review for a clinical practice guideline. Ann Intern Med. 2008;148(5):379-397.

4. Hogan DB. Long-term efficacy and toxicity of cholinesterase inhibitors in the treatment of Alzheimer disease. Can J Psychiatry. 2014;59(12):618-623.
5. Maxwell CJ, Stock K, Seitz D, et al. Persistence and adherence with dementia pharmacotherapy: relevance of patient, provider, and system factors. Can J Psychiatry. 2014;59(12):624-631.

6. Rockwood K. Size of the treatment effect on cognition of cholinesterase inhibition in Alzheimer's disease. J Neurol Neurosurg Psychiatry. 2004;75(5):677-685.

7. Rockwood K, MacKnight C. Assessing the clinical important of statistically significant improvement in anti-dementia drug trials. Neuroepidemiology. 2011;20(2):51-56.

8. Rockwood K, Fay S, Jarrett P, et al. Effect of galantamine on verbal repetition in AD: a secondary analysis of the VISTA trial. Neurology. 2007;68(14):1116-1121.

9. Rockwood K. The importance of measuring executive function when studying the effects of cognition-enhancing agents. Ann Intern Med. 2008;149(5):358-359.

10. Herrmann N, Black SE, Li A, et al. Discontinuing cholinesterase inhibitors: results of a survey of Canadian dementia experts. Int Psychogeriatr. 2011;23(4):539-545.

11. Rosen WG, Mohs RC, Davis KL. A new rating scale for Alzheimer's disease. Am J Psychiatry. 1984;141(11):1356-1364.

12. US Department of Health and Human Services. Food and Drug Administration. Center for Drug Evaluation and Research. Guidance for industry Alzheimer's disease: developing drugs for the treatment of early stage disease [Internet]. Silver Spring (MD): US Department of Health and Human Services; 2013 Feb [cited 2014 Jul 3]. Available from: http://www.fda.gov/downloads/ Drugs/GuidanceComplianceRegulatoryInformation/Guidances/ UCM338287.pdf. p 5.

13. Cummings J, Gould H, Zhong K. Advances in designs for Alzheimer's disease clinical trials. Am J Neurodegener Dis. 2012;1(3):205-216.

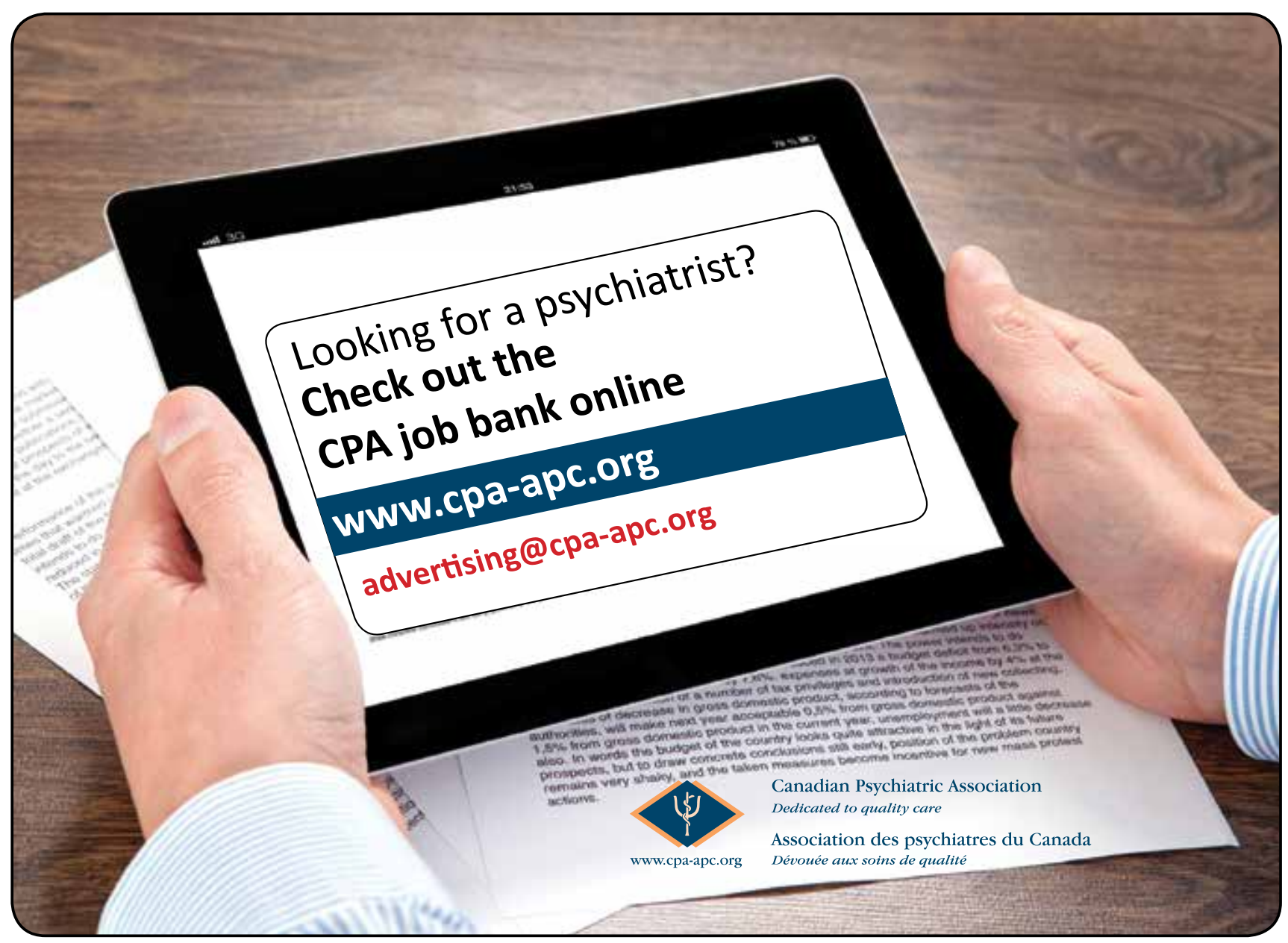

